amount of blood ejected by the ventricles per 1 minute (rate - 3.5-5.5 l). Systolic volume of the heart (CO) - is the amount of blood ejected by the heart ventricles at the same reduction (norm - 50-90 ml). Children with mezosomatotype physique revealed the highest IOC indicators and CO $(5,43 \pm 0,4 \mathrm{l}$ and $66,31 \pm 0,3 \mathrm{ml}$, respectively) $(\mathrm{p} \square \mathrm{o}, 05)$. This indicates a high power of heart contractions. The lowest rates were found in macrosomatotype groups $(\mathrm{IOC}=5,38 \pm 0,2 \mathrm{l}, \mathrm{CO}=63,98 \pm 0,6 \mathrm{ml})$ and microsomatotype groups $(\mathrm{IOC}=5,11 \pm 0,4 \mathrm{l}, \mathrm{CO}=62,61 \pm 1,0$ $\mathrm{ml})$, but the values are within the norm (p円o,05).

Current index adaptive capacity of the cardiovascular system by R.M.Baevskomu (AP) defines the functional status of the patient. Children of all somatotypes index below 2.6, indicating that a satisfactory adaptation of teenagers, high reserve capacity of the heart.

Coefficient efficiency circulation (KEK) is defined as: KEK = (SBP, DBP), heart rate. It describes the costs of the organism in the blood travel in the bloodstream. It was found that macrosomatotype children economical happens spending reserves of the cardiovascular system (indicator KEK $=2975,4 \pm 0,8$ ), compared with microsomatotype children $(K E K=2706,5 \pm 1,0)$ and mezosomatotype children $(K E K=2794 \cdot 5 \pm 1,2)(p \square 0,05)$.

Rufe index reflects the adaptive capacity of the cardiovascular system in response to a graduated exercise. Children of all somatotypes Rufe index showed a below-average level of reserve of the cardiovascular system. Significantly better results were observed in students with mezosomatotype physique.

Determining the type of self-circulation provides an opportunity to assess the level of stress in the regulation of the cardiovascular system. In adolescents, all somatotypes TSC index less than 90 (micro - 84,33 \pm 0,5 ; mezo $-78,82 \pm 0,8$; macro $-82,47 \pm 0,4$ ), which indicates the type of self-regulation of cardiac blood flow (pD 0.05).

Conclusions. Thus, the level of physical health is largely determined by the spare capacity of the cardiovascular system and differ significantly in adolescents with different somatotypes (slow, normal and accelerated). Children with microsomatotype and microsomatotype body type, can be attributed to the group of persons with reduced functional reserves of the cardiorespiratory system and lower compensatory capacity of the organism in response to exercise. Establishing a relationship of morphological and functional characteristics of children of different types of constitution, allows the further development of a fundamental framework for a more complete study of the physiological individuality and proposals for the development of new approaches to preclinical diagnosis of disorders of the cardiorespiratory system and evaluation of the general state of their health.

\title{
Literature
}

1. Yutkina O.S. The functional state of cardio-respiratory system in children, depending on the somatotype. In: Proceedings of the VI Congress of doctors pulmonologists Siberia and the Far East. Far Eastern Scientific Center of Physiology and Pathology of respiration, Amur State Medical Academy, Ministry of Health of the Amur region, Russian respiratory society. 2015. pp 157-161.

2. Yutkina O.S. Status of the cardiorespiratory system in adolescents depending on somatotype. In: Evidence-based medicine - the basis of modern health care. Collection of scientific papers (in the framework of the National Year of combating cardiovascular disease). Institute of Advanced Training of health professionals. 2015. pp 41-43.

3. Yutkina O.S. Constitutional features of children, depending on the physical development.// International scientific review. Number 2015. 2 (3). S. 84-86.

4. Yutkina O.S., Babtsev A.F., Arutyunyan K. The health of children and adolescents based on the results of the automated complex dispensary examination.// Allergology and Immunology. 2014. Vol 15. №2. P.119.

5. Yutkina O.S. Circadian blood pressure profile in younger schoolboys // Proceedings of the V International Scientific and Practical Conference "21st Century: basic science and technology." 2014. Volume 1. pp 45-47.

6. Yutkina O.S., Babtsev A.F., T.A. Metelkina, Amelichkina T.V., Murrieva N.V. Early markers of hemodynamic disorders in children, depending on the physical development of the Amur // Medical Journal. 2014. number 4 (8). S. 84-86.

DOI:10.22448/AMJ.2016.15-16.122-124

UDC 616-053.5:612.112.94

\section{ADAPTATION REACTIONS OF JUNIOR SCHOOL CHILDREN}

Yutkina 0.S.

\section{Amur State Medical Academy, Blagoveshchensk, Russia}

Abstract Non-specific types of adaptive reactions of an organism of children of 6-9 years old were estimated. The analysis of maps of hardware and software inspection of dispensary children was maden. The total number of study included 192 people. The adaptive response of the body in children, depending on the age and gender, was studied using data leukochogram (percentage of lymphocytes in the leucocyte count) (Garkavi, 1998). 
Key words: children, adaptive reactions of an organism, lymphocytes.

Children's protection and young people's health is an important goal of medicine, education, government. The school period is one of the most difficult stages: an intensive growth, the final socialization, hormonal changes, puberty, and formed human health. Currently, widespread development has been a new trend in the theoretical and practical medicine - pre-disease diagnostics - the functional state of the organism, the border between normality and pathology. High incidence of most countries is primarily due to a decrease the body's ability to defend itself, the result of lowering its adaptive capabilities of the complex under the influence of various environmental factors. The problem of adaptation is not by chance called "the problem of the century." The earlier to determine the moment of failure of adaptation mechanisms, the more chances to maintain health, to rehabilitate existing deviations at $[1,2,3]$.

Materials and methods. Assessment of the severity of types of non-specific adaptation reactions of the organism of children, 6-9 years old. The analysis of maps of the hardware and software inspection dispensary children was done. 192 people were examined, where 86 (45\%) female and 106 (55\%) male. Age study - 6-9 years. Sampled on specific somatic scheme Dorokhov and Bahraka: micro, mezo and macrosomatotype.

We have studied the adaptive response of the body in children, depending on their age and gender, using data leykotsitogrammy (percentage of lymphocytes in the leucocyte count) (LH Garkavi, 1998) (Table. 1).

Table 1.

Age-dependent indexes of adaptation reactions on the percentage of limphocytes (L.H. Gakkavi, 1998)

\begin{tabular}{|c|c|c|c|c|c|}
\hline Age & Stress & Training & $\begin{array}{c}\text { Quiet } \\
\text { activating }\end{array}$ & Overactivation & Reactivation \\
\hline 3-国years & $<29,5$ & $29,5-37,5$ & $38-45$ & $45,5-57$ & $>57$ \\
\hline $6-9$ years & $<25$ & $25-32$ & $32,5-40$ & 国历-51 & $>51$ \\
\hline $10-13$ years & $<23$ & $23-30$ & $30,5-38$ & $38,5-48,5$ & $>48$ \\
\hline $14-16$ years & $<20,5$ & $20,5-28,5$ & $29-39$ & 3Е్ర, $-46,5$ & $>46$ \\
\hline Adults & $<20$ & $20-27,5$ & $28-34$ & $34,5-44$ & $>44$ \\
\hline
\end{tabular}

Stress - is established in the evolution of general nonspecific adaptive response of the body in response to strong stimuli of any kind, a reaction in which the protection is intertwined with corruption. Allocated 5 major types of adaptive responses: pathological reactions - stress, reactivation and Antistress reactions - training, relaxing and increased activation of the activation. Each of these reactions corresponds to a certain state of health of the child and level of health. "Perfect health" (rarely or almost never ill children) corresponds to increased activation of stress-response elements in leucocyte count, "average rate" - the calm reaction of activation. Pathological reactions - stress, reactivation - characteristic of the acute period of the disease in children, but the transition to recovery should normally take place on the background of the transition stress Antistress reactions - often in activation reactions after exercise response, and in some cases - directly in the activation reaction.

According to LH Garkavi, in each age group of children, we have identified five clusters corresponding complex changes in the body during five general adaptive reactions (stress, exercise, good activation, enhanced activation and reactivation). We have also taken into account the severity of the reactivity levels for signs of tension in the leukocyte formula [4].

Overall reactivity was determined by translating quantitative indicators in the interest of their sum corresponded to a certain level reactions. All rates were statistically processed with the calculation of averages, the average error rate Student, carried out a correlation analysis with a significance level of $p<0.05$.

Results and discussion. The analysis found that increased activation response was observed in 75 subjects (39\%), calm activation - in $48(25 \%)$, reaction training in $35(18 \%)$, reactivation in $25(13 \%)$, stress $9(5 \%)$. These values indicate that a larger number of study observed homeostasis level, which corresponds to normal health in children aged 6-9 years. Among the microsomatotype girls the majority (43\%) the reaction was traced increased activation and reactivation reactions were observed none of the study (p<0.05). However, among microsomatotype boys reactivation response was observed in a large number (37\%) subjects ( $p<0.05$ ). According to the literature, at the age of about six years in boys begins active growth in girls, this process starts much later - in the nine-eleven, so the age of six, they do not change as fast as the boys, and therefore non-specific adaptation reactions reflect the processes occurring in the body.

Conclusions. Thus, nonspecific reaction adaptation most children were investigated under physiological norm activation. Reactions elevated and quiet activation, characterized by anabolic processes, with a predom- 
inance of synthesis, that is, to accumulate reserves which are necessary for the young and growing organism. Certain types of reactions in children correspond to abnormalities in leukocyte formula. Based on an assessment of the type of reaction, you can pick up specific recommendations for optimizing the health of children.

\section{Literature}

1. Yutkina O.S., Arutyunyan K.A. Clinico-morphological inspection - the method of studying constitutional features of children and adolescents. In the collection: The 11th Sino-Russia Forum of Biomedical and Pharmaceutical Science. The conference proceedings. 2014. Pp 230-232.

2. Yutkina O.S., Babtseva A.F. Daily blood pressure monitoring of teenagers from Blagoveshchensk The collection: The 11th Sino-Russia Forum of Biomedical and Pharmaceutical Science. The conference proceedings. 2014. Pp 233-235.

3. Yutkina O.S., Arutyunyan K.A. The new technologies used in professional surveys of children and teenagers The collection: The 11th Sino-Russia Forum of Biomedical and Pharmaceutical Science. The conference proceedings. 2014. pp 236-237.

4. Yutkina O.S., Arutyuanyan K.A. Flow of pneumonia for children on the modern stage. Amur Medical Journal. 2013. № 2-1 (2). Pp 149-153.

\section{DOI:10.22448/AMJ.2016.15-16.124-125 \\ UDC 616-053.5:159.9.072.432 \\ PSYCHOLOGICAL CHARACTERISTICS OF SCHOOLBOYS DEPENDING ON SOMATOTYPE}

\section{Yutkina 0.S.}

\section{Amur State Medical Academy, Blagoveshchensk, Russia}

Abstract In recent decades, the negative trend to reduce children's health persists. The reason for the formation of diseases in children is a combination of adverse factors: trouble in the perinatal period, deteriorating environmental situation and the characteristics of the psychological type of personality. Total one-third of teens is characterized by the ability to easily express their emotions, to identify and describe what they really feel. Most of the children are characterized by reduced ability or difficulty to the verbalization of emotional states and $25 \%$ of subjects showed a pronounced presence of alexithymia. Alexithymia refers to the risk factors of psychosomatic diseases.

Key words: children, alexithymia, psychosomatic diseases.

In recent decades, the negative trend persists reduce children's health. The main feature of the modern diseases of childhood is the growing prevalence of chronic physical and neuropsychiatric diseases. The reason for the formation of diseases in children is a combination of adverse factors: trouble in the perinatal period, deteriorating environmental situation and the characteristics of the psychological personality type [1,2,3].

Alexithymia - psychological characteristics of the individual, characterized by obstruction or complete inability to accurately describe the person's own emotional experiences and understand another person's feelings, difficulties in determining the difference between feelings and bodily sensations, fixation on external events to the detriment of the inner experiences.

Alexithymia ("without words for feelings") - psychological characteristics of personality: the difficulty in identifying and describing their own emotions and the emotions of other people; difficulty in the difference between emotions and bodily sensations; decreased ability to symbolize, for fantasy; focus on external events, at the expense of inner experiences; the tendency to the concrete, logical thinking with a deficit of emotional reactions.

The problem of the study of alexithymia in modern science is polydisciplinary character. The main directions of the study of this phenomenon (clinical and psychological) do not give an unambiguous interpretation of its formation and development mechanisms. According to current literature alexithymia refer to the risk factors of psychosomatic diseases.

Materials and methods. Objective: to study the level of alexithymia in adolescents, depending on their physical development. The study was conducted on the basis of secondary school № 5 , among children under school age (16-17 years), using a procedure - Toronto alexithymia scale (the TAS), adapted to the Institute. VI spondylitis, which is aimed at the study of alexithymia as a personality traits. In the analysis of the responses received, according to the procedure, an overall score is calculated, which corresponds to one of the personality types: less than 62 points - "not alexithymical" personality type. Group from 62 to 74 points relate to risk. "Alexithymical" personality type - more than 74 points. According to our survey results the average score was 66.3 on a scale that has already belongs to a risk group. Indicators statistically processed with the calculation of averages, the average error rate Student.

Results and discussion. Spend anthropometry 60 healthy children, of which with average physical development showed $53 \%$ of adolescents; below average - $18 \%$ higher than the average $-28 \%(p<0.05)$. When 